\title{
Loss of myocardial protection against myocardial infarction in middle-aged transgenic mice overexpressing cardiac thioredoxin-1
}

\author{
Verónica D'Annunzio ${ }^{1,5, *}$, Virginia Perez ${ }^{1, *}$, Tamara Mazoㄹ, Marina C. Muñoz ${ }^{2,5}$, \\ Fernando P. Dominici, ${ }^{2,5}$, María C. Carreras ${ }^{3,5}$, Juan José Poderoso ${ }^{3,5}$, Junichi \\ Sadoshima ${ }^{4}$ and Ricardo J. Gelpi ${ }^{1,5}$ \\ ${ }^{1}$ Institute of Cardiovascular Physiopathology and Department of Pathology, Faculty of Medicine, University of Buenos Aires, \\ Buenos Aires, Argentina \\ ${ }^{2}$ Institute of Chemistry and Biological Physical Chemistry, School of Pharmacy and Biochemistry, University of Buenos Aires, \\ Buenos Aires, Argentina \\ ${ }^{3}$ Laboratory of Oxygen Metabolism, University Hospital, University of Buenos Aires, Buenos Aires, Argentina \\ ${ }^{4}$ Department of Cell Biology and Molecular Medicine, Rutgers New Jersey Medical School, Newark, NJ, USA \\ ${ }^{5}$ Member of the National Council of Scientific and Technological Research (CONICET), Buenos Aires, Argentina \\ * These authors have contributed equally to this work \\ Correspondence to: Ricardo J. Gelpi, email: rgelpi@fmed.uba.ar
}

Keywords: myocardial infarction, ischemia/reperfusion, thioredoxin-1, middle-aged, Gerotarget

Received: December 21,2015 Accepted: January 30, 2016

Published: February 25, 2016

\section{ABSTRACT}

Thioredoxin-1 (Trx1) protects the heart from ischemia/reperfusion (I/R) injury. Given that the age at which the first episode of coronary disease takes place has considerably decreased, life at middle-aged (MA) emerges as a new field of study. The aim was determine whether infarct size, Trx1 expression and activity, Akt and GSK-3 $\beta$ were altered in young $(Y)$ and MA mice overexpressing cardiac Trx1, and in a dominant negative (DN-TrX1) mutant of Trx1. Langendorff-perfused hearts were subjected to 30 minutes of ischemia and 120 minutes of reperfusion (R). We used 3 and 12 month-old male of wild type (WT), Trx1, and DN-Trx1. Trx1 overexpression reduced infarct size in young mice (WT-Y: $46.8 \pm 4.1 \%$ vs. TrX1-Y: $27.6 \pm 3.5 \%, p<$ $0.05)$. Trx1 activity was reduced by $52.3 \pm 3.2 \%(p<0.05)$ in Trx1-MA, accompanied by an increase in nitration by $17.5 \pm 0.9 \%$, although Trx1 expression in transgenic mice was similar between young and middle-aged. The expression of p-Akt and p-GSK$3 \beta$ increased during reperfusion in Trx1-Y. DN-Trx1 mice showed neither reduction in infarct size nor Akt and GSK-3 $\beta$ phosphorylation. Our data suggest that the lack of protection in Trx1 middle-aged mice even with normal Trx1 expression may be associated to decreased Trx1 activity, increased nitration and inhibition of p-Akt and p-GSK-3 $\beta$.

\section{INTRODUCTION}

Thioredoxin-1 (Trx1) is one of the most important cellular antioxidant systems known to date [1]. Particularly, Trx 1 exerts an increase in lifespan and has a protective effect against ischemia/reperfusion (I/R) injury, reducing the infarct size [2-4]. In this sense, Nakamura et al. [5] showed in patients subjected to bypass surgery that thioredoxin inactivation was a deleterious mechanism in I/R injury. Similarly, Tao et al. [3] showed that administration of Trx 1 in vivo exerts significant protective effects on myocardial apoptosis decreasing myocardial infarct size, by inhibiting p38-MAPK activation. Thus, it is clear that $\operatorname{Trx} 1$ has a protective effect against I/R injury. However, most of these studies were performed in young and healthy rodents [2-4].

It is also widely known that I/R injury is exacerbated in elderly populations and that many of the protective mechanisms lose their effect with advanced age $[6,7]$. But it is not clear whether this also occurs in middle-aged, when the deleterious effects of aging are already taking place $[8,9]$. This lack of studies in middle-aged is striking, 
Table 1: Left ventricular systolic and diastolic function.

\begin{tabular}{|c|c|c|c|}
\hline & Groups & Baseline & 30min Rep \\
\hline \multirow{6}{*}{$\begin{array}{l}\text { LVDP } \\
(\mathrm{mmHg})\end{array}$} & Wt-Y & $88.2 \pm 2.3$ & $27.9 \pm 4.7^{*}$ \\
\hline & Wt-MA & $80.5 \pm 8.5$ & $22.1 \pm 7.8^{*}$ \\
\hline & \begin{tabular}{|l|} 
Trx $1-Y$ \\
\end{tabular} & $87.7 \pm 6.6$ & $30.6 \pm 3.5^{*}$ \\
\hline & Trx1-MA & $87.1 \pm 7.8$ & $29.2 \pm 7.7^{*}$ \\
\hline & DN-Trx1-Y & $91.2 \pm 5.4$ & $32.4 \pm 5.2 *$ \\
\hline & DN-Trx1-MA & $92.7 \pm 8.2$ & $31.9 \pm 4.7^{*}$ \\
\hline \multirow{6}{*}{$\begin{array}{l}\text { LVEDP } \\
(\mathrm{mmHg})\end{array}$} & $\mathrm{Wt}-\mathrm{Y}$ & $7.8 \pm 1.1$ & $28.5 \pm 5.8^{*}$ \\
\hline & Wt-MA & $8.8 \pm 2.8$ & $30.2 \pm 8.5^{*}$ \\
\hline & Trx1-Y & $7.1 \pm 0.8$ & $21.4 \pm 7.1^{*}$ \\
\hline & Trx1-MA & $7.6 \pm 1.1$ & $23.3 \pm 6.6^{*}$ \\
\hline & DN-Trx1-Y & $8.2 \pm 1.8$ & $34.5 \pm 4.2 *$ \\
\hline & DN-Trx1-MA & $8.5 \pm 0.9$ & $29.4 \pm 3.9 *$ \\
\hline \multirow{6}{*}{$\begin{array}{l}\mathrm{LV}+\mathrm{dP} / \mathrm{dt}_{\max } \\
(\mathrm{mmHg} / \mathrm{sec})\end{array}$} & Wt-Y & $3151 \pm 206$ & $1285 \pm 196^{*}$ \\
\hline & Wt-MA & $2949 \pm 217$ & $1199 \pm 257 *$ \\
\hline & Trx 1-Y & $2927 \pm 301$ & $1399 \pm 128^{*}$ \\
\hline & Trx1-MA & $3228 \pm 339$ & $1320 \pm 239 *$ \\
\hline & DN-Trx1-Y & $3308 \pm 287$ & $1289 \pm 117^{*}$ \\
\hline & DN-Trx1-MA & $3189 \pm 294$ & $1229 \pm 133^{*}$ \\
\hline
\end{tabular}

LVDP: Left ventricular developed pressure; LVEDP: Left ventricular end diastolic pressure; $\mathrm{LV}+\mathrm{dP} / \mathrm{dt}_{\text {max }}$ Left ventricular maximal rate of pressure increase. Rep: Reperfusion. *: $\mathrm{p}<0.05$ vs respective baseline value. Wt: wild type; Trx 1: transgenic mice thioredoxin-1 overexpression; DN-Trx 1: Dominant negative for endogenous Trx1 in mice hearts Y: Young; MA: middle-aged.

since ischemic episodes in patients begins at that stage of life, and they are not exclusive of advanced age $[8,9]$. There are numerous experimental evidence showing that mice older than 18 months exhibit a significant increment in reactive oxygen and nitrogen species (ROS and RNS) thus exacerbating I/R damage [6, 7]. Regarding Trx1 and aging, it has been demonstrated that infarct size and apoptosis increase in older animals due to thioredoxin physiological inactivation $[10,11]$. However, it is known that even though oxidation processes start when life begins; it is in middle-aged that they reach sufficient levels to trigger deleterious mechanisms on different cell components [12], and this ROS increases is able to modify expression and/or activity of several proteins [13-15]. However if Trx1, at this stage of life, suffers alterations in its expression and/or activity has not been studied, neither have modifications in the infarct size behavior.

It has been also widely demonstrated that the activation of the PI3K/Akt complex triggers intracellular events, such as the inactivation of glycogen synthase kinase $3 \beta$ (GSK-3 $\beta$ ) [16]. This is a consequence of its phosphorylation by Akt, which confers protection against $\mathrm{I} / \mathrm{R}$ damage, decreasing the infarct size [16-18]. Adluri et al. [19] showed that $\operatorname{Trx} 1$ overexpression induces Aktsignaling pathway compared to wild type mice during ischemic stress, and this could be related to a reduction in oxidative stress. Regarding GSK-3 $\beta$ and Trx1, Schenkel et al. [20] report that in later stages there is a decrease of Trx1 in parallel with some signaling proteins, including GSK-3 $\beta$ activation that is involved in maladaptative cardiac remodeling and ventricular dysfunction. For these reasons, it would be interesting to study the activation/ inactivation of Akt and GSK- $3 \beta$ in an acute $\mathrm{I} / \mathrm{R}$ protocol with overexpression of $\operatorname{Trx} 1$, and to compare the results between young and middle-aged mice.

Thus, the first objective of our work was to evaluate infarct size and ventricular function in young and also in middle-aged transgenic (TG) mice overexpressing Trx1. To further study the role of $\operatorname{Trx} 1$ in cardioprotection, we also use a dominant negative (DN-Trx1) mutant (C32S/C35S) of Trx1, with cardiac overexpression and inactivation of $\operatorname{Trx} 1$. Since $\operatorname{Trx} 1$ presents a decrease in activity and protein nitration in older mice, a second objective was to determine if middle-aged TG mice overexpressing Trx 1 also present an increase in these inactivation mechanisms. Finally, a third objective was to examine if the protection conferred by Trx 1 involves Akt and GSK-3 $\beta$ inhibition/phosphorylation.

\section{RESULTS}

Table 1 shows the systolic behavior throughout the left ventricular developed pressure (LVDP, $\mathrm{mmHg}$ ) and the maximal rate of rise of left ventricular pressure 
$\left(\mathrm{LV}+\mathrm{dP} / \mathrm{dt}_{\max }\right)$, at baseline and 30 minutes of reperfusion. In all groups, LVDP and $\mathrm{LV}+\mathrm{dP} / \mathrm{dt}_{\max }$ were significantly lower compared to pre-ischemic values, but showed no significant differences among groups. Regarding myocardial stiffness, represented by the left ventricular end of diastolic pressure (LVEDP, $\mathrm{mmHg}$ ), we found a significant increase at 30 minutes of reperfusion respective pre-ischemic values without changes among the groups.

Figure 1 (Panel A) shows the infarct size in all experimental groups. The $\operatorname{Trx} 1$ overexpression significantly reduced the infarct size in young mice (WTY: $52.3 \pm 3.2 \% v s$. Trx1-Y: $27.6 \pm 3.5 \%, p<0.05$ ), while middle-aged animals did not exhibit this infarct size reduction (WT-MA: $51.8 \pm 2.6 \% v s$. Trx1-MA: $49.1 \pm 6.3 \%$ ). Panel B shows representative slices of the different experimental groups.

Figure 2 shows the behavior of $\operatorname{Trx} 1$ expression (Panel A), activity (Panel C) and nitration (Panel D). In normoxic conditions in young and middle-aged TG mice there were a significant increase in Trx 1 expression (Panel A), meanwhile Trx1 levels were lesser in WT middle-aged than in young mice $(\mathrm{Nx}-\mathrm{Y}: 1.1 \pm 0.1$ vs. NXMA: $0.42 \pm 0.05, p<0.05$ ). At 15 minutes of reperfusion, Trx 1 expression decreased significantly in wild type mice reaching a $47 \%$ in young and $42 \%$ in middle-aged of reduction compared with pre-ischemic values (Panel A), and in TG mice Trx1 levels was similar to their respective normoxic values. Trx1 activity was reduced in Trx1-MA compared with Trx 1-Y mice (Panel C). Directly related to the previous findings, there was a $17.5 \pm 0.9 \%$ increase in the nitration of Trx 1-MA mice compared to Trx1-Y (Panel D). Taken together, these data suggest that in Trx 1 middleaged mice, even with normal Trx 1 expression, there is inactivation of $\operatorname{Trx} 1$ that involves protein nitration. Panel B shows ponceau S-stained blot, as loading control, and representative blots of Trx1.

Figure 3 shows the cardiac expression of Akt phosphorylation at Ser473 residue, in the cytosolic fraction in normoxic conditions (matched time) and after ischemia/reperfusion (15 minutes of reperfusion) in young (Panel A) and middle-aged mice (Panel B). Panel $\mathrm{C}$ shows representative blots and ponceau S-stained blot of total and phosphorylated Akt. We showed a significant increase in p-Akt Ser473 in the group of young animals with overexpression of Trx 1 during reperfusion compared to pre-ischemic values (Trx1-Y; normoxic: $1.02 \pm 0.07$ AU vs. I/R: $1.47 \pm 0.08 \mathrm{AU} ; p<0.05)$, meanwhile in WT young group there were no changes at reperfusion period (Panel A). Nevertheless, p-Akt Ser473 values in middleaged mice were similar between wild type and $\operatorname{Tr} 1$ before ischemia and during reperfusion (I/R: WT-MA $0.97 \pm 0.14$ AU vs. Trx1-MA 0.86 \pm 0.10 AU) (Panel B). Thus, our data shows an increase in p-Akt Ser473 phosphorylation in Trx1-Y mice hearts while there is no increase in middleaged ones. Regarding p-Akt Thr308 site (data not shown), there were no significant differences within the groups of young animals before ischemia and during reperfusion and middle-aged animals.

Figure 4 shows the cardiac expression of p-GSK$3 \beta$ Ser9 residue, in the cytosolic fraction in normoxic conditions and after ischemia/reperfusion (15 minutes of reperfusion in young (Panel A) and middle-aged mice (Panel B). It can be observed that there are no significant differences in the expression of total GSK-3 $\beta$ among all the groups studied (Panel C), while a significant increase of p-GSK-3 $\beta$ is observed in the group of young animals

A

B

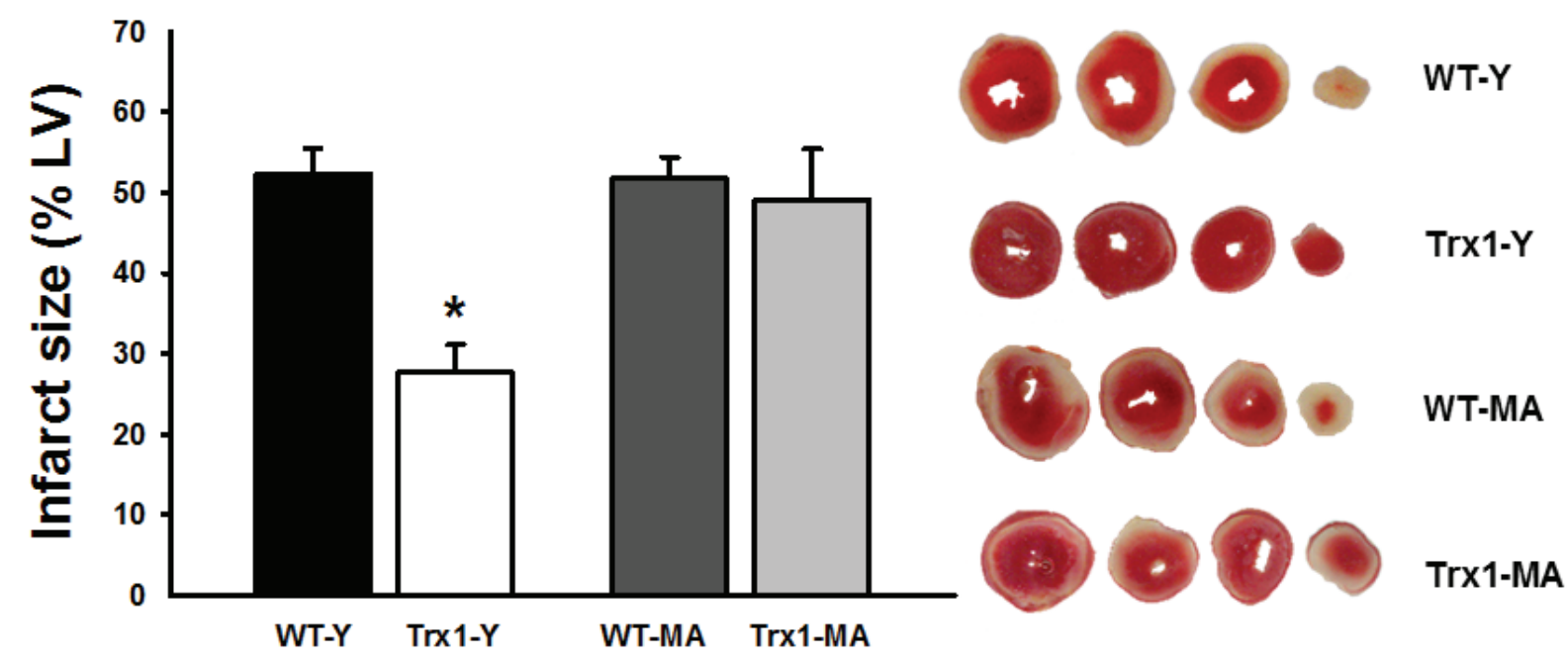

Figure 1: Infarct size expressed as a percentage of the total left ventricular area. Infarct size decreased significantly in Trx1 young group but this cardioprotective effect was abolished in Trx1 middle-aged. Panel B shows representative slices of the different experimental groups. Data are represented as mean +/- SEM. *: $p<0.05 v s$. WT-Y. WT-Y: wild type in young animals (3 month-old); WTMA: wild type in middle-aged animals (12 month-old); Trx1-Y: thioredoxin-1 young group; Trx1-MA: thioredoxin-1 middle-aged group. 


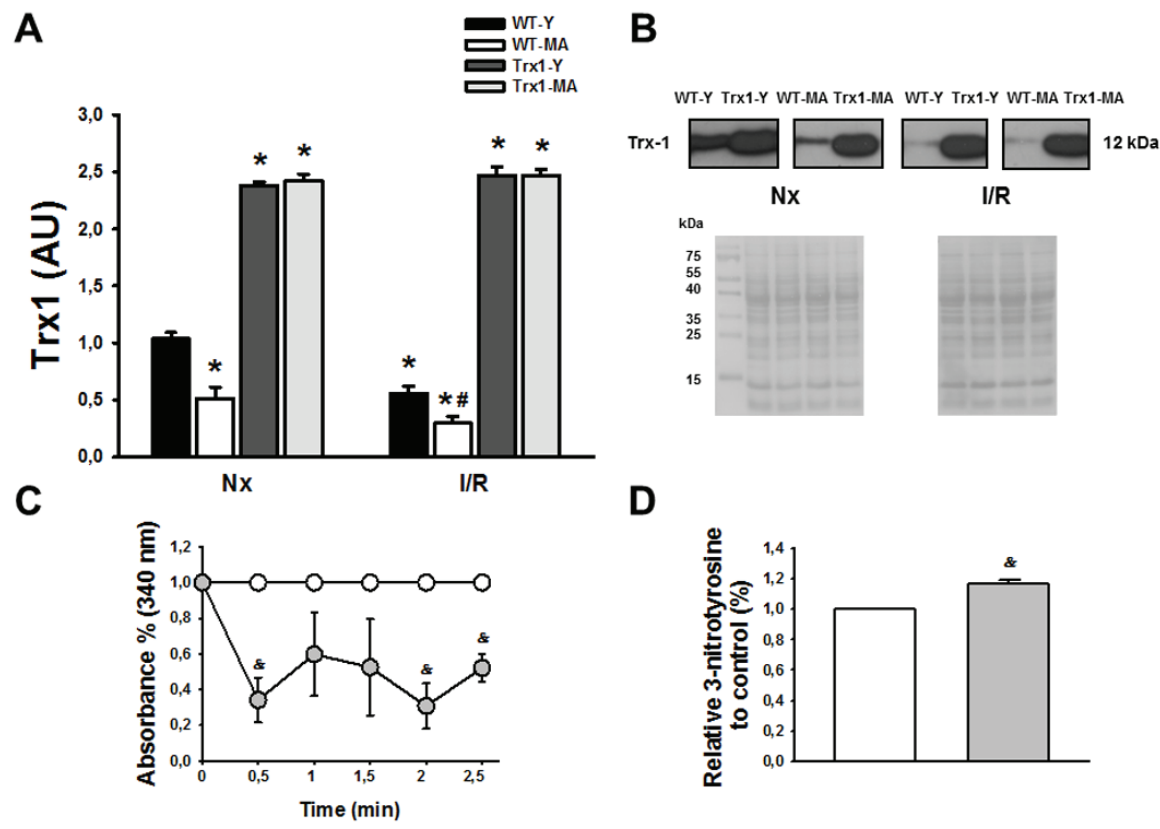

Figure 2: Panel A shows an increased in Trx1 expression in transgenic animals, both in young (Y) and middle-aged (MA) group in normoxic ( $\mathbf{N x}$ ) conditions and after ischemia/reperfusion protocol. The levels of Trx1 in wild type mice (WT) decreased at reperfusion (after 30 minutes of ischemia and 15 minutes of reperfusion) in young and middle-aged animals, but in transgenic mice the levels of Trx1 remains in similar values as normoxic conditions. Panel B show Ponceau S-stained blot, as loading control, and representative blots of Trx1. Panel C shows that in transgenic mice the activity was lower in Trx1 young group compared with Trx1 middleaged group. Finally, in panel D we observed an increased in Trx1 nitration in middle-aged group compared with young group. Data are represented as mean + - SEM. * $: p<0.05$ vs. WT animals. \#: $p<0.05 v s$. Nx respective conditions; \&: $p<0.05$ vs. Trx 1 young group.

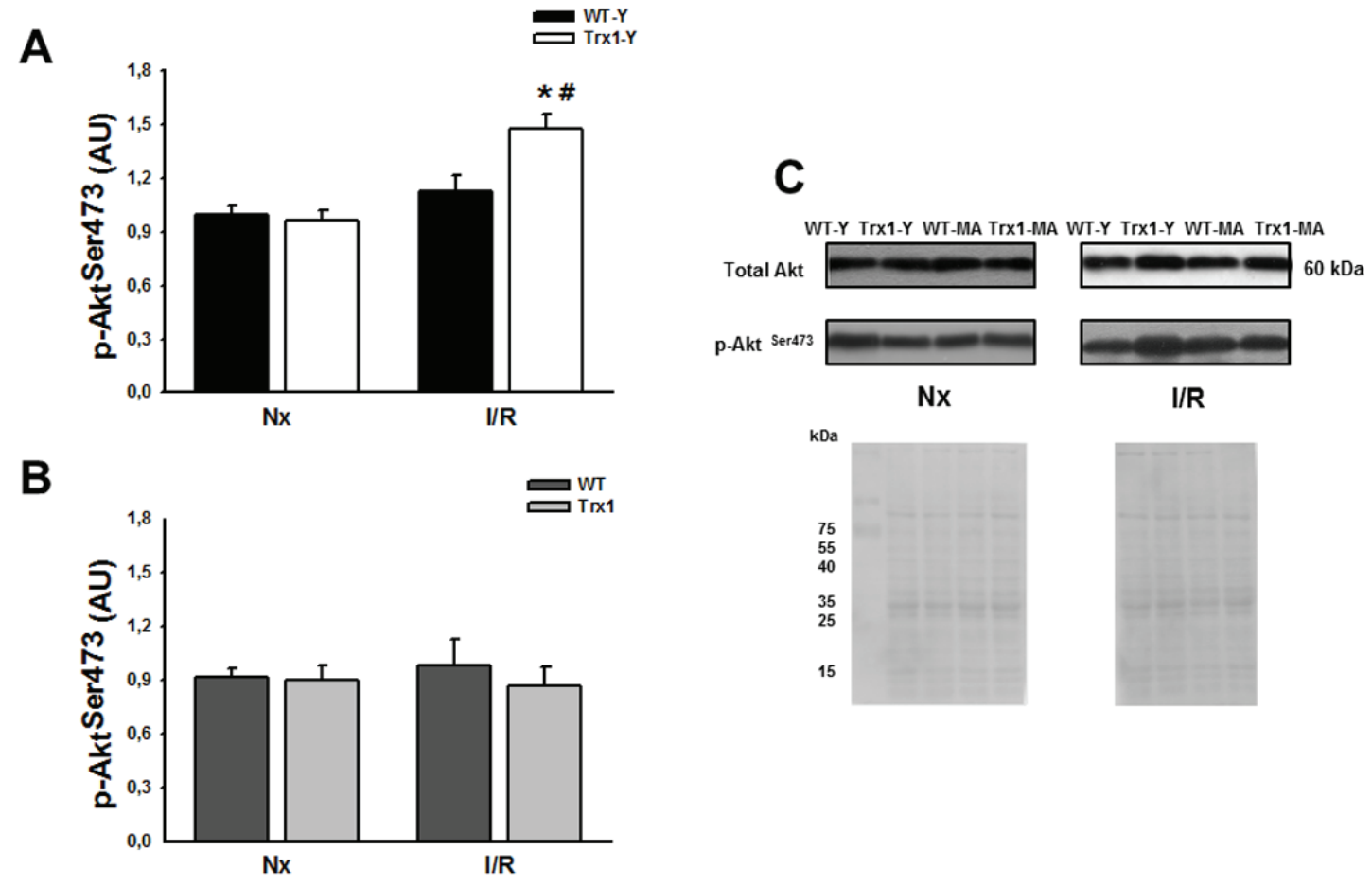

Figure 3: Akt phosphorylation (Ser 473) protein expression in the cytosolic fraction of normoxic (Nx) and ischemia/ reperfusion protocols $(\mathbf{I} / \mathbf{R})$ in young (Panel $\mathbf{A})$ and middle-aged (Panel B) mice. There were not significantly changes in the cytosolic Akt protein expression (Panel C). Also, not significantly changes were detected, in the cytosolic p-Akt Ser 473 protein expression in Trx 1 and WT middle-aged groups, however in Trx 1 young group a significantly enhanced of Akt phosphorylation after I/R was detected. Panel C shows Ponceau S-stained blot, as loading control, and representative blots of total and phosphorylated Akt. Data are represented as mean +/- SEM. *: $p<0.05$ vs normoxic Trx1; \#: $p<0.05 v s$ WT-Y I/R. WT-Y: wild type in young animals (3 month-old); WT-MA: wild type in middle-aged animals (12 month-old); Trx1-Y: thioredoxin-1 young group; Trx1-MA: thioredoxin-1 middle-aged group. 
overexpressing Trx 1 compared with its pre-ischemic value (Trx1-Y: normoxic: 1.01 $\pm 0.01 \mathrm{AU} v s . \mathrm{I} / \mathrm{R}: 1.30 \pm 0.10 \mathrm{AU}$, $p<0.05)$ (Panel A). However, this increase in the GSK$3 \beta$ phosphorylation is not evidenced in the middle-aged groups, both in WT mice and in Trx1 mice (WT-MA: normoxic: $1.02 \pm 0.14 \mathrm{AU}$; I/R: $1.13 \pm 0.1 \mathrm{AU}$; Trx1-MA: normoxic: $1.08 \pm 0.09$ AU; I/R: $1.23 \pm 0.13$ AU) (Panel B). Panel $\mathrm{C}$ represents representative blots and ponceau S-stained blot of total and p-GSK-3 $\beta$.

In order to confirm that cardioprotection afforded by Trx 1 involved Akt and GSK-3 $\beta$ phosphorylation, additional experiments in DN-Trx1 mice with cardiac overexpression of a redox inactive Trx 1 mutant were performed. We detected that infarct size was similar between WT and DN-Trx1 in young (WT-Y: $52.3 \pm 3.2 \%$ vs. DN-Trx1-Y: $54.3 \pm 4.0 \%$ ) and in middle-aged mice (WT-MA: $51.8 \pm 2.6 \%$ vs. DN-Trx1-MA: $56.6 \pm 4.2 \%$ ). The Akt and GSK-3 $\beta$ phosphorylation in young and also in middle-aged DN-Trx1 did not show changes between basal and ischemia/reperfusion conditions. These results are consistent with the lack of cardioprotection in DNTrx1 mice (Figure 5).

\section{DISCUSSION}

The present study shows, as expected, that young mice overexpressing Trx 1 have a smaller infarct size compared to their corresponding WT mice. However, this infarct size reduction was observed neither in Trx 1 middle-aged nor in young and middle-aged DN-Trx1 mice. Although we found a significant increase in Trx 1 levels in young and middle-aged transgenic mice, Trx1 activity was less in middle-aged mice and this findings was accompanied by an increase in the nitration of this protein. Finally, we also demonstrated that phosphorylation of Akt and GSK-3 $\beta$ were increased only in young Trx 1 mice without any change in middle-aged mice and in DN-Trx1 mice.

Since we did not evidence infarct size reduction in middle-aged Trx1 mice, we mesaured Trx1 expression and activity in these animals. After ischemia/reperfusion protocol in WT mice we evidenced a significant reduction in Trx 1 levels both in young and middle-aged animals. With regard to our findings, other authors have evidenced that during reperfusion after an ischemic period, there is an increase in peroxynitrite concentration, and it has been reported to produce cellular damage by lipid peroxidation, DNA fragmentation, and in addition induced depletion of antioxidants $[21,22]$ including thioredoxin [6]. However, in mice overexpressing thioredoxin we evidenced that during reperfusion Trx1 levels were similar to preischemic values. Although protein levels remained intact,
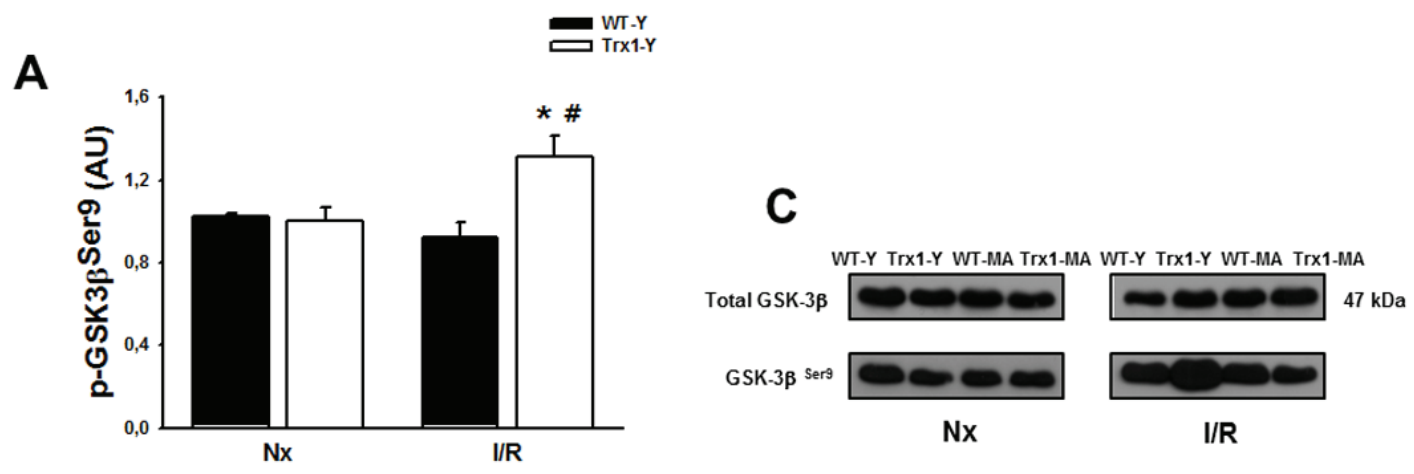

B
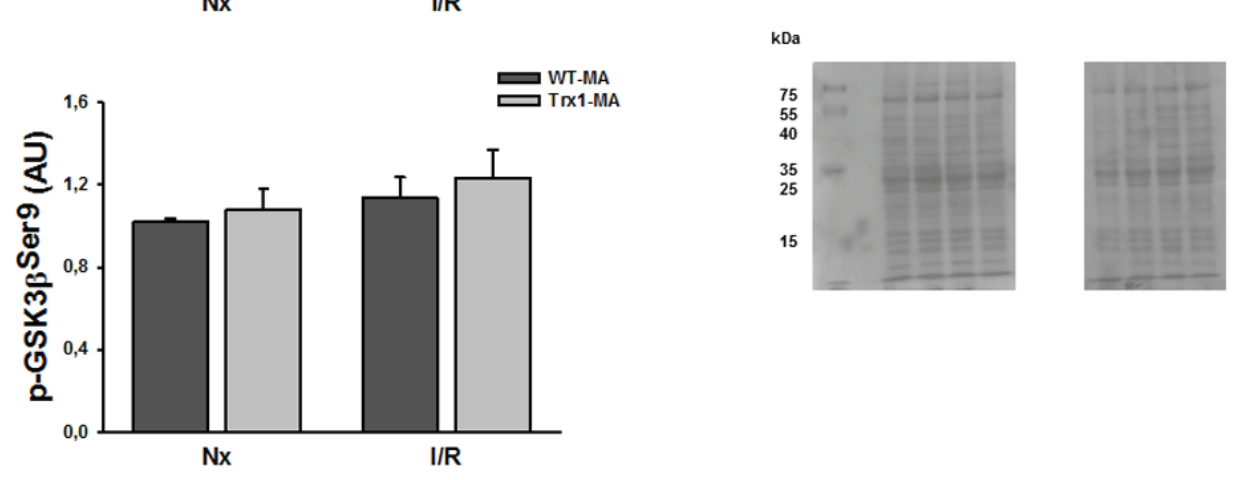

Figure 4: pGSK-3ß Ser 9 protein expression in the cytosolic fraction of normoxic (Nx) and ischemia/reperfusion protocols (I/R) in young (Panel A) and middle-aged (Panel B) mice. There were not significantly changes in the cytosolic GSK-3 $\beta$ protein expression (Panel C). Also, not significantly changes in the cytosolic in p-GSK-3 $\beta$ Ser 9 protein expression were detect in Trxland WT middle-aged groups, however in Trx1 young group, a significantly enhanced of GSK-3 $\beta$ phosphorylation after I/R was detected. Panel C shows Ponceau S-stained blot, as loading control, and representative blots. Data are represented as mean $+/-$ SEM. *: $p$ $<0.05$ vs normoxic Trx1; \#: $p<0.05$ vs WT-Y I/R. WT-Y: wild type in young animals (3 month-old); WT-MA: wild type in middle-aged animals (12 month-old); Trx1-Y: thioredoxin-1 young group; Trx1-MA: thioredoxin-1 middle-aged group. 
we found a decrease in Trx 1 activity with an increase nitration, only in middle-aged mice. It is well known, that thioredoxin can suffer post-translational modifications such as S-nitrosylation, oxidation and nitration [23, 1, 10, 24]. The first one has beneficial effects improving Trx 1 cardioprotective activity through apoptosis reduction [23]. Oxidation partially inactivates it while nitration causes Trx 1 totally irreversible inactivation resulting in the attenuation of its biological functions [1, 10, 24]. Thus, it is clear that in our study the increase in Trx 1 nitration produced the reduction in its activity and consequently there was no evidence of the beneficial effects on middleaged mice infarct size. As previously mentioned, Zhang et al. [11] demonstrated that Trx activity is decreased only in the aging hearts of 20 month-old mice by posttranslational nitrative modification. Interestingly our data shows that already at 12 month-old, when the deleterious effects of pro-oxidant mechanisms associated to aging are not completely established, are enough to detect and increase in Trx 1 nitration and a consequent inactivation. It is probable that these post-translational modifications are related to the fact that no protection was evidenced in the size of the infarct. Neither were changes in the phosphorylation of Akt and GSK-3 $\beta$ in middle-aged mice.
Regarding Akt/p-Akt Ser473 in particular, Adluri et al. [19] demonstrated that Trx1 overexpression induces Akt-signaling pathway compared to WT mice during ischemic stress, and this could be related to a reduction in oxidative stress. These authors used a chronic model of myocardial infarction and showed that the Akt was phosphorylated several days after the ischemia insult. However, our research is the first that involves Akt as the probable target for thioredoxin to provide protection in an ischemia/reperfusion in vitro model in an acute way. This was supported by the fact that in DN-Trx1 mice phosphorylation of Akt and GSK-3 $\beta$ was not observed and therefore the infarct size was not reduced. Regarding interactions, it has been demonstrated that Trx 1 is capable of indirectly phosphorylating Akt in other pathologies such as myocardial remodelling and cancer $[21,25,26]$. This protein has been extensively studied and has a major role in physiological and pharmacological protection mechanisms; it is also part of the RISK-pathway protection system $[25,27,28]$. A possible mechanism by which Trx relates to Akt is through PTEN, because it has been shown that Trx1 inhibits PTEN [29], as this mediator modulates activation of $\mathrm{PI} 3 \mathrm{~K} / \mathrm{Akt}$ complex triggering intracellular events that confer protection against I/R injury [28].

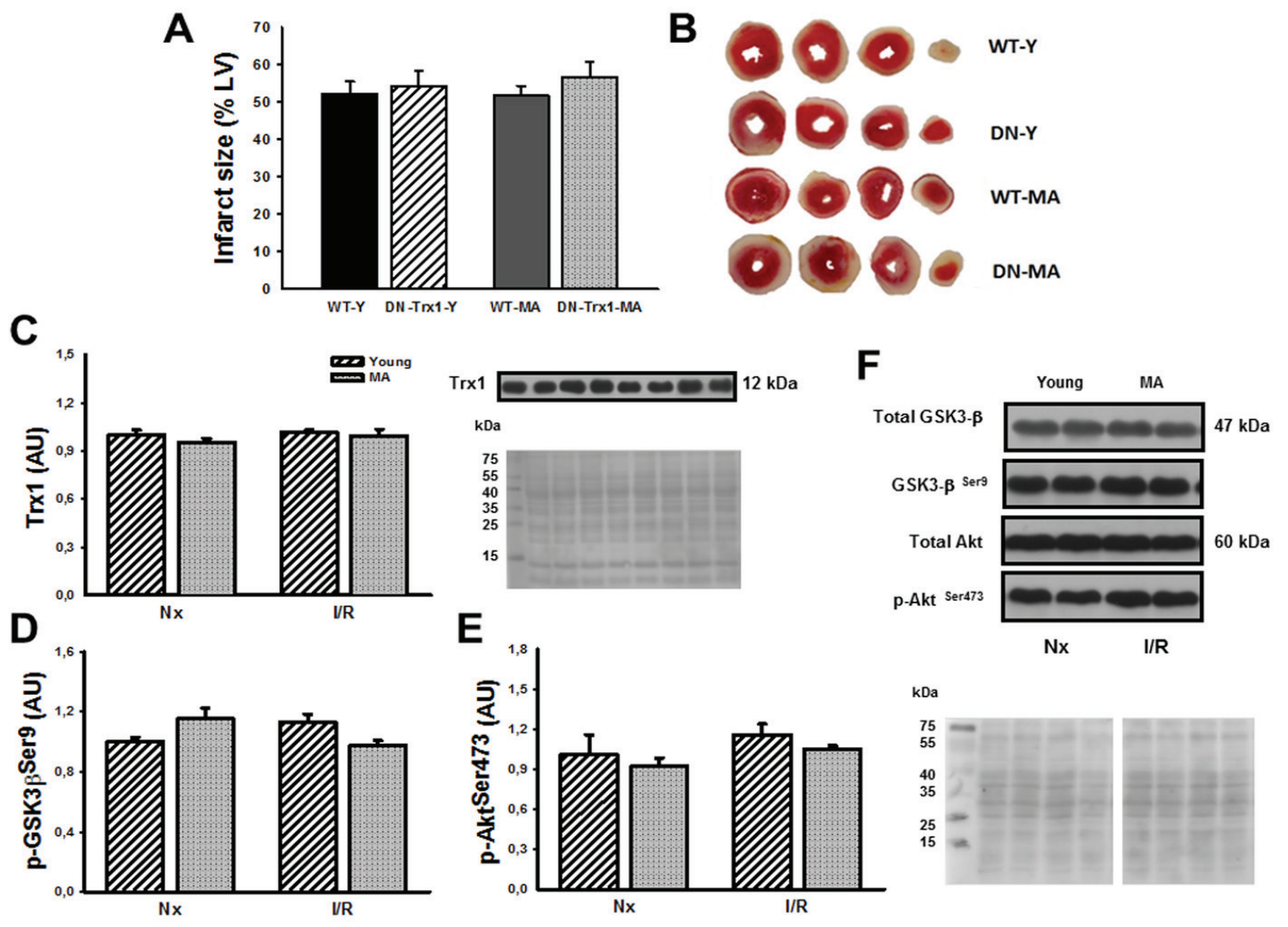

Figure 5: We showed DN-Trx1 mice results in order to confirm that the cardioprotection conferred by Trx1 involves Akt and GSK-3ß inhibition/phosphorylation. nfarct size (Panel A), Trx1 expression (Panel C), p-Akt Ser473 (Panel D) and p-GSK$3 \beta$ Ser9 (Panel E) were similar between wild type (WT) and in dominant negative for Trx1 (DN-Trx1) in young and middle-aged mice. Panel B shows representative slide of infarct size. Panel F shows Ponceau S-stained blot, as loading control, and Akt/ GSK-3 $\beta$ representative blots. Data are represented as mean $+/$ - SEM. 
A limitation to our study is that we did not evaluate the interaction between PTEN and Trx1, nevertheless when we used DN-Trx1mice we could not detect neither cardioprotection nor activation of pro-survival proteins. Therefore, our data suggest that overexpression of Trx 1 protects the myocardium against ischemia/reperfusion injury by activating Akt and GSK-3 $\beta$.

Our results confirm that the protection conferred by the overexpression of Trx1 would be at least partially due to inactivation of GSK-3 $\beta$, given that in DN-Trx1 the lack of GSK-3 $\beta$ phosphorylation showed that this pro-survival protein was not activated [30]. To our knowledge, this is a novel finding since, no studies have assessed if Trx1 has an effect on GSK-3 $\beta$ in an acute way, once reperfusion is initiated, in young and middle-aged mice comparatively. Unlike our findings, Schenkel et al. [20] demonstrated that after myocardial infarction, even though Trx1 appears to make an important contribution to the reduced $\mathrm{H}_{2} \mathrm{O}_{2}$ concentration, is not enough to produce modifications in GSK-3 $\beta$ in the early stages in a chronic model without reperfusion. This difference is important; given that Zhai et al. [30] demonstrated that the inhibition of GSK-3 $\beta$ does not produce a cardioprotective effect, but exacerbates the ischemic injury in a mice model with ischemia without reperfusion. However, it does have a protective effect against ischemic injury followed by reperfusion through the modulation of autophagy [30]. Thus, in concordance with our findings, the inactivation of GSK-3 $\beta$ would have a protective effect in $\mathrm{I} / \mathrm{R}$ models, like our experimental model. This inactivation of GSK-3 $\beta$ would have a beneficial effect in young mice overexpressing Trx1; meanwhile there is no evidence of phosphorylation or infarct reduction in middle-aged Trx 1 and in DN-Trx1 mice.

In agreement with previous studies using isolated hearts mice preparations [31] in our study, overexpression of Trx1 in young mice reduced infarct size but was unable to improve ventricular function (contractile state and myocardial stiffness). The absence of improvement of LV function in our study may be due to the presence of myocardial stunning areas peripheral to the infarct zone $[31,32]$. In this sense, it has been well shown that the presence of a certain degree of post-ischemic dysfunction (stunned myocardium) reverts approximately after 48/72 hours of reperfusion; therefore the change in infarct size in acute experiments does not influence significantly the ventricular function [32].

In summary, Trx1 overexpression reduced, as expected, infarct size in young mice and this cardioprotection included an increase of Akt and GSK-3 $\beta$ phosphorylation. The lack of protection in middle-aged mice was related to the reduction in Trx1 activity and increase in Trx1 nitration. These data, and the fact that in DN-Trx1 we did not detect a reduction in the infarct size, suggest a cardioprotective role of Trx 1 activating Akt and GSK-3 $\beta$ in an acute way.

\section{MATERIALS AND METHODS}

\section{Animal care}

All procedures performed in these studies involving animals were in accordance with the ethical standards of the Animal Care and Research Committee of the University of Buenos Aires (CICUAL UBA \# 0037016/2012). FVB mice were housed in ventilated cages with a 12 hours light/dark cycle and controlled temperature $\left(20-22^{\circ} \mathrm{C}\right)$, and fed with normal chow and water ad libitum.

\section{Experimental protocols}

Three and twelve month-old male hearts from: a) transgenic mice with cardiac- specific overexpression of Trx1 (generated on an FVB background using the $\alpha$-myosin heavy chain promoter to achieve cardiac-specific expression), b) DN-Trx1 mice was generated by mutation of 32Cys and 35Cys of hTrx 1 to Ser using QuikChange (Stratagene, La Jolla, California, USA) [33]. This redox inactive mutant of Trx1 works as a dominant negative for endogenous Trx 1 in mice hearts, and c) its corresponding wild type mice $(\mathrm{FVB})$ were randomized into six groups: 1) wild type young (WT-Y, $n=8$ ); 2) Trx1 young (Trx1-Y, $n=7) ; 3$ ) wild type middle-aged (WT-MA, $n=7$ ); 4) Trx 1 middle-aged (Trx1-MA, $n=6$ ); 5) DN-Trx1 young (DNTrx1-Y, $n=8$ ); and 6) DN-Trx1middle-aged (DN-Trx1MA, $n=7)$. For the middle-aged group, mice should be at least 10 month-old; the upper age limit for the middleaged group is typically 14-15 month-old [34]. For this reason we decided to use 12 month-old as middle-aged mice.

\section{Isolated mice heart}

In all groups we used isolated mice hearts perfused according to Langendorff technique and performed 30 minutes of global ischemia and 120 minutes of reperfusion. The mice were anesthetized by an intraperitoneal injection of sodium pentobarbital (150mg/ $\mathrm{Kg}$ ) and sodium heparin (500 IU/kg bow, i.p). After ensuring sufficient depth of anesthesia, hearts were excised and the aorta was immediately cannulated with a 21 gauge cannula. After that, hearts were perfused according to Langendorff technique with Krebs bicarbonate-buffered solution containing (in $\mathrm{mM}$ ): $\mathrm{NaCl} 118.5, \mathrm{KCl} \mathrm{4.7}$, $\mathrm{NaHCO}_{3} 24.8, \mathrm{KH}_{2} \mathrm{PO}_{4} 1.2, \mathrm{Mg} \mathrm{SO}_{4} 1.2, \mathrm{CaCl}_{2} 1.5$ and glucose 10 . This solution was continuously bubbled with $95 \% \mathrm{O}_{2}$ and $5 \% \mathrm{CO}_{2}(\mathrm{pH}=7.4)$ at $37{ }^{\circ} \mathrm{C}$. During this time a small fluid-filled balloon, which was connected via a thin plastic catheter (P50) to a pressure transducer 
(Deltram II, Utah Medical System), was inserted into the left ventricle (LV) via the left atrium. The catheter with the transducer was positioned in such a way that it secured the position of the balloon in the left ventricle for measurement of LV pressure. The latex balloon was filled with water to achieve an LV end diastolic pressure of 8-10 mmHg (LVEDP). Two electrodes were sutured and connected to a pacemaker to produce a constant heart rate of $472 \pm 30$ beats/min. We also recorded the coronary perfusion pressure (CPP) through a pressure transducer connected to the perfusion line. All hearts were perfused at constant flow at $4.01 \pm 0.27 \mathrm{ml} / \mathrm{min}$. Coronary flow was adjusted to obtain a CPP of $73 \pm 3 \mathrm{mmHg}$ during the initial stabilization period and was then maintained constant throughout the experiment. LVDP and $\mathrm{LV}+\mathrm{dP} / \mathrm{dt}_{\text {max }}$ were used as contractile state indexes. LVEDP, a myocardial stiffness index in the isovolumic heart, was also measured.

\section{Infarct size measurement}

The assessment of the infarct size was performed using 2,3,5-triphenyltetrazolium chloride (TTC). After 120 minutes of reperfusion, the hearts were frozen and cut into $1 \mathrm{~mm}$ transverse slices from apex to base. Sections were incubated for 20 minutes in $1 \%$ TTC $\left(\mathrm{pH} \mathrm{7.4,37}{ }^{\circ} \mathrm{C}\right)$ and then immersed in $10 \%$ formalin. With this technique, viable sections were stained red, while the non-stained sections corresponded to the infarct area. Sections were traced to acetate sheets and planimetered (Image Pro Plus, version 4.5). Infarct size was expressed as a percentage of the left ventricular area.

\section{Insulin reduction assay for $\operatorname{Trx} 1$}

The activity of Trx1 in the heart was determined by the insulin reduction assay, according to the method described by Holmgren and Bjornstedt (1995) with a slight modification. Hearts form TG Trx1 young mice $(n=5)$ and MA $(n=6)$ were homogenated with ice-cold phosphate buffered saline (PBS) containing $10 \mu \mathrm{g} / \mathrm{ml}$ PMSF (phenylmethanesulfonylfluoride), $0.5 \mu \mathrm{g} / \mathrm{ml}$ aprotinin and $0.5 \mu \mathrm{g} / \mathrm{ml}$ leupeptin. An equal amount of protein (50 $\mu \mathrm{g})$ in a volume of $13.28 \mu \mathrm{l}$ was preincubated with 3.32 $\mu \mathrm{l}$ of the dithiothreitol (DTT) activation buffer (100 mM Tris-Cl [pH 7.5], $2 \mathrm{mM}$ ethylenediaminetetraacetic acid (EDTA), $1 \mathrm{mg} / \mathrm{ml}$ bovine serum albumin (BSA), and 2 $\mathrm{mM}$ DTT) at $37{ }^{\circ} \mathrm{C}$ for 15 minutes. The samples were then mixed with $183.3 \mu \mathrm{l}$ of reaction mixture $(100 \mathrm{mM}$ Tris-Cl [pH 7.5], $2.0 \mathrm{mM}$ EDTA, $1.0 \mu \mathrm{g}$ human Trxreductase and $140 \mu \mathrm{M}$ insulin) and were incubated at 25 ${ }^{\circ} \mathrm{C}$. Reaction is started by adding nicotinamide adenine dinucleotide phosphate (NADPH) $(0.2 \mathrm{mM})$. As a control, the samples were mixed with the reaction mixture without Trx-reductase. Changes in absorbance in the absence of Trx-reductase were subtracted from those in the presence of Trx-reductase [33].

\section{Western blot}

We performed additional experiments to obtain hearts samples ( $n=5$ in each group) in order to Western blot analysis. Heart tissue was homogenized in ice for approximately 2 minutes with extraction buffer $(\mathrm{pH}$ 7.4), composed of: Tris $1.2 \mathrm{mM}, \mathrm{NaCl} 0.36 \mathrm{mM}$, sodium dodecyl sulfate (SDS) $0.1 \%$, Triton $1 \%$, DTT $0.2 \mathrm{mM}$, protease and phosphatase inhibitors cocktail (Thermo Scientific) at a rate of $500 \mu \mathrm{L}$ buffer every $150 \mathrm{mg}$ of tissue using a PRO 200 Scientific INC homogenizer. Subsequently, homogenates were centrifuged at 12000 rpm during 20 minutes at $4{ }^{\circ} \mathrm{C}$. The supernatant protein concentration was quantified with Bradford method. After protein quantification $50 \mu \mathrm{g}$ of each sample were separated by $16 \%$ Tricine-SDS-PAGE gels for Trx 1 and cardiac nitration, and by $12 \%$ SDS-PAGE gels for Akt and GSK-3 $\beta$. Then the gels were transferred to a polyvinylidene fluoride (PVDF) membrane (Thermo Scientific) that was later blocked with 5\% BSA for two hours at room temperature. Subsequently, the membrane was incubated with anti-Trx1 (1:1000) (Cell Signaling), anti-3-nitrotyrosine antibody (1:2000), anti-p-Akt for serine residue 473 and threonine residue 308 (1:1000) (Cell Signaling), and anti-p-GSK-3 $\beta$ for serine residue 9 (1:1000) (Cell Signalling) over night at $4{ }^{\circ} \mathrm{C}$ with agitation. It was later incubated with anti-rabbit secondary antibody conjugated with horseradish peroxidase (HRP, 1:15000) (Millipore) for an hour at room temperature. The membrane was developed with photographic plates (Kodak) and Super Signal West Pico Chemiluminescent Substrate (Thermo Scientific). Proteins expression was quantified by densitometry with Image Gauge 4.0 software (Fujifilm) compared to the charge control values, Ponceau Red staining (Sigma) measured in the same membranes and was used as loading control.

\section{Statistical analysis}

Data are expressed as mean \pm standard error of the mean (SEM). Inter-group comparisons were performed using analysis of variance and then the Bonferroni test for multiple comparisons. $p<0.05$ was considered statistically significant.

\section{ACKNOWLEDGMENTS}

Grants: This study was supported by the University of Buenos Aires UBACYT\# 20020110100159, and the National Agency for Technological and Scientific Promotion: PICT 0258. 


\section{CONFLICTS OF INTEREST}

The authors declare that they have no conflict of interest.

\section{REFERENCES}

1. Ago T, and Sadoshima J. Thioredoxin and ventricular remodeling. J Mol Cell Cardiol. 2006; 41:762-773.

2. Turoczi T, Chang VW, Engelman RM, Maulik N, Ho YS, and Das DK. Thioredoxin redox signaling in the ischemic heart: an insight with transgenic mice overexpressing Trx 1 . J Mol Cell Cardiol. 2003; 35:695-704.

3. Aota M, Matsuda K, Isowa N, Wada H, Yodoi J, and Ban T. Protection against reperfusion-induced arrhythmias by human thioredoxin. J Cardiovasc Pharmacol. 1996; 27:727732.

4. Tao L, Gao E, Bryan NS, Qu Y, Liu HR, Hu A, Christopher TA, Lopez BL, Yodoi J, Koch WJ, Feelisch M, and Ma $\mathrm{XL}$. Cardioprotective effects of thioredoxin in myocardial ischemia and reperfusion: role of S-nitrosation. Proc Natl Acad Sci USA. 2004; 101:11471-11476.

5. Nakamura H, Vaage J, Valen G, Padilla CA, Björnstedt M, and Holmgren A. Measurements of plasma glutaredoxin and thioredoxin in healthy volunteers and during open-heart surgery. Free Radic Biol Med. 1998; 24:1176-1186.

6. Przyklenk K. Efficacy of cardioprotective 'conditioning' strategies in aging and diabetic cohorts: the co-morbidity conundrum. Drugs Aging. 2011; 28:331-343.

7. Whittington HJ, Harding I, Stephenson CI, Bell R, Hausenloy DJ, Mocanu MM, and Yellon DM. Cardioprotection in the aging, diabetic heart: the loss of protective Akt signalling. Cardiovasc Res. 2013; 99:694704.

8. Uhl GS, and Farrell PW. Myocardial infarction in young adults: risk factors and natural history. Am Heart J. 1983; 105:548-553.

9. Cohen D, Manuel DG, Tugwell P, Ramsay T, and Sanmartin C. Inequity in primary and secondary preventive care for acute myocardial infarction? Use by socioeconomic status across middle-aged and older patients. Can J Cardiol. 2013; 29:1579-1585.

10. Tao L, Jiao X, Gao E, Lau WB, Yuan Y, Lopez B, Christopher T, Ramachandra Rao SP, Williams W, Southan G, Sharma K, Koch W, and Ma XL. Nitrative inactivation of thioredoxin-1 and its role in postischemic myocardial apoptosis. Circulation. 2006; 114:1395-1402.

11. Zhang H, Tao L, Jiao X, Gao E, Lopez BL, Christopher TA, Koch W, and Ma XL. Nitrative thioredoxin inactivation as a cause of enhanced myocardial ischemia/reperfusion injury in the aging heart. Free Radic Biol Med. 2007; 43:39-47.

12. Fan Q, Chen M, Fang X, Lau WB, Xue L, Zhao L, Zhang H, Liang YH, Bai X, Niu HY, Ye J, Chen Q, Yang X, and Liu M. Aging might augment reactive oxygen species
(ROS) formation and affect reactive nitrogen species (RNS) level after myocardial ischemia/reperfusion in both humans and rats. Age (Dordr). 2013; 35:1017-1026.

13. Babušíková E, Lehotský J, Dobrota D, Račay P, and Kaplán P. Age-associated changes in $\mathrm{Ca}(2+)$-ATPase and oxidative damage in sarcoplasmic reticulum of rat heart. Physiol Res. 2012; 61:453-460.

14. Choksi KB, Nuss JE, DeFord JH, and Papaconstantinou J. Mitochondrial electron transport chain functions in long-lived Ames dwarf mice. Aging (Albany NY), 2011; 3(8):754-767

15. Kim JY, Kim OY, Paik JK, Kwon DY, Kim HJ, and Lee $\mathrm{JH}$. Association of age-related changes in circulating intermediary lipid metabolites, inflammatory and oxidative stress markers, and arterial stiffness in middle-aged men. Age (Dordr). 2013; 35:1507-1519.

16. Fang SJ, Wu XS, Han ZH, Zhang XX, Wang CM, Li $\mathrm{XY}, \mathrm{Lu} \mathrm{LQ}$, and Zhang JL. Neuregulin-1 preconditioning protects the heart against ischemia/reperfusion injury through a PI3K/Akt-dependent mechanism. Chin Med J (Engl). 2010; 123:3597-3604.

17. Tsai HJ, Huang SS, Tsou MT, Wang HT, Chiu JH. Role of Opioid Receptors Signaling in Remote Electrostimulation - Induced Protection against Ischemia/Reperfusion Injury in Rat Hearts. PLoS One. 2015; 10(2) doi: 10.1371/journal. pone. 0138108 .

18. Ji L, Zhang X, Liu W, Huang Q, Yang W, Fu F, Ma H, Su H, Wang H, Wang J, Zhang H, and Gao F. AMPKRegulated and Akt-Dependent Enhancement of Glucose Uptake Is Essential in Ischemic Preconditioning-Alleviated Reperfusion Injury. PLoS One. 2013; 8:e69910.

19. Adluri RS, Thirunavukkarasu M, Zhan L, Akita Y, Samuel SM, Otani H, Ho YS, Maulik G, and Maulik N. Thioredoxin 1 enhances neovascularization and reduces ventricular remodeling during chronic myocardial infarction: a study using thioredoxin 1 transgenic mice. J Mol Cell Cardiol. 2011; 50, 239-247.

20. Schenkel PC, Tavares AM, Fernandes RO, Diniz GP, Ludke AR, Ribeiro MF, Araujo AS, Barreto-Chaves ML, and Belló-Klein A. Time course of hydrogen peroxidethioredoxin balance and its influence on the intracellular signalling in myocardial infarction. Exp Physiol. 2012; 97:741-749.

21. Dhalla NS, Elmoselhi AB, Hata T, and Makino N. Status of myocardial antioxidants in ischemia-reperfusion injury. Cardiovasc Res. 2000; 47:446-456.

22. Qin CX, Williams SJ, and Woodman OL. Antioxidant activity contributes to flavonol cardioprotection during reperfusion of rat hearts. Free Radic Biol Med. 2011; 51:1437-1444.

23. Cardone MH, Roy N, Stennicke HR, Salvesen GS, Franke TF, Stanbridge E, Frisch S, and Reed JC. Regulation of cell death protease caspase- 9 by phosphorylation. Science. 1998; 282:1318-1321. 
24. Rassaf $\mathrm{T}$, and Luedike P. Between nitros(yl)ation and nitration: regulation of thioredoxin-1 in myocardial ischemia/reperfusion injury. J Mol Cell Cardiol. 2010; 49:343-346.

25. Yang XM, Krieg T, Cui L, Downey JM, and Cohen MV. NECA and bradykinin at reperfusion reduce infarction in rabbit hearts by signaling through PI3K, ERK, and NO. J Mol Cell Cardiol. 2004; 36:411-421.

26. Sartelet H, Rougemont AL, Fabre M, Castaing M, Duval M, Fetni R, Michiels S, Beaunoyer M, and Vassal G. Activation of the phosphatidylinositol 3'-kinase/AKT pathway in neuroblastoma and its regulation by thioredoxin 1. Hum Pathol. 2011; 42:1727-1739.

27. Hausenloy DJ, Tsang A, and Yellon DM. The reperfusion injury salvage kinase pathway: a common target for both ischemic preconditioning and postconditioning. Trends Cardiovasc Med. 2005; 15:69-75.

28. Zu L, Zheng X, Wang B, Parajuli N, Steenbergen C, Becker $\mathrm{LC}$, and Cai ZP. Ischemic preconditioning attenuates mitochondrial localization of PTEN induced by ischemiareperfusion. Am J Physiol Heart Circ Physiol. 2011; 300:H2177-H2186.

29. Meuillet EJ, Mahadevan D, Berggren M, Coon A, and Powis G. Thioredoxin-1 binds to the C2 domain of PTEN inhibiting PTEN's lipid phosphatase activity and membrane binding: a mechanism for the functional loss of PTEN's tumor suppressor activity. Arch Biochem Biophys. 2004; 429:123-133.

30. Zhai P, Sciarretta S, Galeotti J, Volpe M, and Sadoshima J. Differential roles of GSK-3 $\beta$ during myocardial ischemia and ischemia/reperfusion. Circ Res. 2011; 109:502-511.

31. Ashrafian H, Czibik G, Bellahcene M, Aksentijević D, Smith AC, Mitchell SJ, Dodd MS, Kirwan J, Byrne JJ, Ludwig C, Isackson H, Yavari A, Støttrup NB, et al. Fumarate is cardioprotective via activation of the Nrf2 antioxidant pathway. Cell Metab. 2012; 15:361-367.

32. Cohen MV, Yang XM, Neumann T, Heusch G, and Downey JM. Favorable remodeling enhances recovery of regional myocardial function in the weeks after infarction in ischemically preconditioned hearts. Circulation. 2000; 102;579-583.

33. Yamamoto M, Yang G, Hong C, Liu J, Holle E, Yu X, Wagner T, Vatner SF, and Sadoshima J. Inhibition of endogenous thioredoxin in the heart increases oxidative stress and cardiac hypertrophy. J Clin Invest. 2003; 112:1395-1406.

34. Flurkey K, Currer JM, and Harrison DE. The Mouse in Aging Research. In: The Mouse in Biomedical Research, 2nd edn, ed. Fox JG et al., 2007, pp. 637-672. American College Laboratory Animal Medicine (Elsevier), Burlington, MA. 